\title{
Letters and words in word identification
}

\author{
JOHN A. UMANSKY and SUSAN M. CHAMBERS \\ Deakin University, Belmont, Geelong, Victoria 3217, Australia
}

\begin{abstract}
Studies by Barron and Henderson (1977) and Johnson (1975) provide evidence that whole words may be the unit of identification in word perception, rather than single letters. Johnson found that words were matched faster than a letter to the first letter in a word. Barron and Henderson found faster matching times for words than for legal nonword items in a lettermatching task. These findings support the interpretation that words are identified before individual letters. If so, a word-frequency effect should be expected. Experiments 1 and 2 tested for word vs. first-letter-in-word differences, as well as for a word-frequency effect in simultaneous and delayed visual matching tasks. In the simultaneous task, first letters in words were matched faster than words. In the delayed task, there was no difference between matching words or matching the first letters in words. With both tasks there was a word-frequency effect for word matches but not for first-letter-in-word matches. In Experiment 3, first-letter matching time was unrelated to word frequency or lexical status, although it did vary with orthographic legality. These results, on the whole, are consistent with a race model in which identifications take place simultaneously at word, letter-cluster, and letter levels, rather than a sequential model in which the whole word is identified before the component letters.
\end{abstract}

The units used to identify words remains a fundamental issue for psychologists studying word identification. Cattell (1886) proposed that words were identified as whole entities, whereas Pillsbury (1897) suggested that words may be identified letter by letter. More recently, Johnson (1975) advanced a hierarchical "topdown" model of word identification in which words are identified as whole units before the individual letters are identified. In contrast to Johnson's hierarchical model of word identification is the race model put forward by Chambers and Forster (1975), which proposes that the identification processes of words and letters in words proceeds simultaneously.

The empirical basis for Johnson's model comes mainly from his 1975 study. In a bimodal (auditoryvisual) delayed matching task, Johnson found that it took longer to match a letter to the first letter in a word (e.g., T-TABLE) than to match a word to a word (e.g., TABLE-TABLE). Furthermore, no difference was observed between a word match and a letter match (e.g., TABLE-TABLE vs. T-T). Johnson interpreted the first result as support for the hypothesis that the whole word is identified before the individual letters and that an individual letter could be identified only through word disintegration. The second result supported the contention that both words and single letters are analyzed as units and that words are not identified serially as a collection of letters. Johnson (1977, Note 1)

The research reported here is part of the $\mathrm{PhD}$ program of the first author, with the supervision of the second author. The work was supported by a postgraduate research award from the Commonwealth Department of Education, Australia, to John A. Umansky. The authors would like to thank Ken Forster for his comments on the manuscript. Requests for reprints may be sent to John A. Umansky, Deakin University, School of Education, Belmont, Geelong, Victoria 3217, Australia. also provides supporting evidence based on the role of length for word, legal nonword, and illegal nonword stimuli. Using the same task as in the 1975 study, he demonstrated that when words (e.g., BLUSH-BLUSH) or legal nonwords (e.g., BLOSH-BLOSH) were matched, no length effects were present. On the other hand, when the stimuli were illegal nonwords (e.g., BSHOL-BSHOL), length effects were found. These results suggested to Johnson that words and legal nonwords were identified as whole units, whereas illegal nonwords were identified via their component letters.

Barron and Henderson (1977), in a simultaneous matching task, required participants to respond to the first letter in words and legal nonwords. Both the target and stimulus were whole items (e.g., TABLETABLE), and the task was to respond "same" or "different" to the first letter only. They found faster matching times for words than for legal nonword items. Although their experiment did not have a word-match control, they concluded that the word-familiarity effect resulted from the word items being processed as whole word entities. Their conclusion suggests, as does Johnson's (1975), that the whole word is identified before the individual letters.

Massaro and Klitzke (1977) claim that the conclusion that a word is identified faster than the first letter in a word in Johnson's (1975) experiment is unjustified, since an alternative interpretation is possible, namely, that the identification of a part in a whole (e.g., TTABLE) is a task different from the identification of a whole in a whole (e.g., TABLE-TABLE). McNeill and Lindig (1973) also point out that a mismatch between the target item and the search item increases response time. The fastest levels of responding occur when the target and the search item match. Therefore, Johnson's result of the first letter in a word taking longer than the 
word in a matching task may be irrelevant to the unit-ofperception issue. It may indicate only that the mismatch that existed in the letter-to-word match condition (i.e., T-TABLE) resulted in relatively long response times.

The conclusion that word identification takes place at the whole word level before the identification of smaller units (e.g., letters and letter clusters) is inconsistent with the race model of Chambers and Forster (1975). Their model is based on results from a simultaneous matching task in which whole letter strings of the same type font were judged "same" or "different." A wordfrequency effect was found for "same" word items, as well as faster matching times for words than for legal and illegal nonwords. Additionally, legal nonwords were matched faster than illegal nonwords. For "different" items, the response times were dependent on the number of letters that needed to be identified before a "different" decision could be made.

Apart from the finding of a word-frequency effect, the finding of a word/legal nonword difference also suggests that word identification is based on analysis at the lexical level rather than on orthographic analysis, since, in the Chambers and Forster (1975) experiment, the word and legal nonword pairs were matched for orthographic structure. Furthermore, an analysis of the bigram-frequency (BF) and trigram-frequency (TF) counts (Mayzner \& Tresselt, 1965; Mayzner, Tresselt, $\&$ Wolin, 1965) demonstrated no significant correlations with response times.

Johnson's (1975) hierarchical model could account for the "same" responses found by Chambers and Forster (1975), but it would be unable to explain the "different" responses. The race model was proposed to explain both "same" and "different" results within one model. The model depends on the critical assumption that letters are identified faster than letter clusters, which in turn are identified faster than words, an assumption that is incompatible with Johnson's model.

Chambers and Forster (1975) put forward a model in which identification and comparison occur simulta. neously at the word, letter-cluster, and letter levels. At the letter level, letters are analyzed as individual units, and any attempt to identify a letter string takes place sequentially. At the letter-cluster level, orthographic information is used to identify the letter strings. At the word level, identification is based on the whole word using lexical access. The decision time, "same" or "different," for any one item depends on the first level of analysis to yield the basis for a satisfactory decision. The number of identifications and comparisons required before a decision is made will vary and will be reflected in response times.

Using hypothetical values, Chambers and Forster (1975) provide a concrete example of their model, assuming that identification time for letters, letter clusters, and words are 50, 75, and $200 \mathrm{msec}$, respectively, and that a comparison at any level requires $50 \mathrm{msec}$, the iden- tification of a five-letter word in a simultaneous matching task for "same" items would take $750 \mathrm{msec}[(10) \times$ $50 \mathrm{msec})+(5 \times 50 \mathrm{msec})]$ at the letter level. At the letter-cluster level, for a three-cluster item, identification would take $600 \mathrm{msec}[(6 \times 75 \mathrm{msec})+(3 \times 50 \mathrm{msec})]$. At the word level identification time would be $450 \mathrm{msec}$ $[(2 \times 200 \mathrm{msec})+(50 \mathrm{msec})]$.

For "same" responses in a simultaneous word matching task, the complete item needs to be identified and a comparison needs to be made. Under these conditions, responses for word items would be determined by the word level of analysis, since lexical information can be used for these items, and two identifications and a comparison would be faster at the word level of analysis than would be the case at the letter and letter-cluster levels of analysis. In addition, a word-frequency effect would be expected, since it is assumed that word identification is based on the location of a matching lexical entry and that the lexicon is ordered in terms of frequency. For legal nonwords, regular orthographic information is present, and analysis could be completed at the letter-cluster level. Responses for these items would be slower than for words (approximately $600 \mathrm{msec}$ vs. $450 \mathrm{msec}$ ), but faster than for illegal nonwords for which identification must occur at the letter level of analysis (approximately $750 \mathrm{msec}$ ).

For "different" responses, very different results are predicted. When all letters are different, only one letter in each string needs to be identified $[(2 \times 50 \mathrm{msec})+$ $(50 \mathrm{msec})=150 \mathrm{msec}]$, reducing the time to arrive at a "different" decision and eliminating word-nonword effects, since identification can be based on the letter level of analysis for any letter string. Chambers and Forster (1975) demonstrated that increasing the number of shared letters in the "different" items increased the time to respond to those items. Also, decisions were slower for illegal nonwords than for words and legal nonwords. When "different" items have multiple shared letters, a letter level of analysis is less likely to control the decision process.

The hierarchical and race models make contradictory predictions about the speed of identifying the first letter in a word relative to the word itself. Whereas Johnson's (1975) model predicts that the first letter in a word will take longer to identify than the word will, the race model predicts that the first letter in the word will be identified faster than the word. Both models are supported by empirical data, but the paradigms upon which they are based differ. Johnson's model is based on a delayed, bimodal (auditory-visual), same-different matching task, whereas the empirical data base for the race model comes from a paradigm using a simultaneous, unimodal (visual), same-different matching task.

The present experiments use both a simultaneous and a delayed unimodal (visual) same-different matching task; the task is either to match whole words or to match the first letters in words. In the first-letterin-word condition for both simultaneous and delayed 
conditions, the target and stimulus consisted of whole words (e.g., TABLE-TABLE) as opposed to the stimuli used by Johnson (1975), in which the target was a letter on its own (e.g., T-TABLE). The use of whole words as targets may result in a lateral masking effect, increasing the response times to the first-letter-in-word condition. Such an effect, if present, should bias the experiment in favor of Johnson's model.

One variable that can be used to test the predictions of the two models is that of word frequency, familiar words as opposed to unfamiliar words. The wordfrequency effect has been demonstrated in identification threshhold experiments (Solomon \& Postman, 1952), lexical decision tasks (Forster \& Chambers, 1973; Rubenstein, Lewis, \& Rubenstein, 1971), and samedifferent matching tasks (Chambers \& Forster, 1975). In the present task, according to Johnson's (1975) model, and assuming high-frequency words are identified faster than low-frequency words, a word-frequency effect would be predicted for both the word and the firstletter-in-the-word conditions, since for both conditions it is assumed that the word must be identified first. The race model would predict a word-frequency effect in the word condition but not in the first-letter-in-word condition, since responses in the first-letter-in-word condition would be based on decisions from the letter level of analysis, which is completed prior to a word level of analysis.

There are conflicting results relating to word-frequency effects using a bimodal same-different task. Johnson (1975) reported pilot data that indicated that a wordfrequency effect was not present in his particular task. This may be due to an artifact of the design. In Johnson's initial task, the target was the same on 12 of 24 trials within a blocked presentation. The repetitions of items within the experiment may have led participants to assign new frequencies to the stimuli (Nakatani, 1973; Scarborough, Cortese, \& Scarborough, 1977). The effect of situational frequency provides an alternative account of the lack of a word-frequency effect found by Johnson (1975). In a subsequent study, Johnson (1977) refers to an unpublished experiment in which the target varied on every trial and a frequency effect was still not detected. Using the same task, with a blocked presentation and with the target words occurring only once within the experiment, Umansky (Note 2, Experiment 1) demonstrated that for "same" responses in the word condition, high-frequency words were matched faster than lowfrequency words. For the first-letter-in-word condition and for "different" responses, no frequency effect was found. In a further experiment (Umansky, Note 2, Experiment 2), a word-frequency effect was found when words and legal and illegal nonword stimuli were presented in random order but not when each type was presented in separate blocks.

A methodological problem with Johnson's (1975) paradigm concerns the timing between an auditorily presented cue and the visually presented stimulus. The interval was approximately $1 \mathrm{sec}$. Since words vary in vocalization time, the $1-\mathrm{sec}$ interval would have varied according to the time taken to say the word. Also, the presentation of auditory and visual cues was manually controlled, which would be a further source of variance in the 1 -sec interval. These variations may not have been constant across high- and low-frequency words. Such a confounding should account for the variability in the results using the bimodal task and could have lessened the probability of observing a frequency effect.

Experiment 1 was designed to examine some of the theoretical, empirical, and methodological problems arising from Johnson's (1975) model of word identification. Using a unimodal (visual) matching task, the validity of the hypothesis that words are identified before their component letters was tested further.

\section{EXPERIMENT 1}

In this experiment, word frequency was manipulated in word and first-letter-in-word matching tasks using simultaneous and delayed stimulus presentations. The hierarchical and race models make different predictions for these conditions.

The hierarchical model would predict that word matches should be faster than first-letter-in-word matches. Also, if there is a word-frequency effect, it will be present in all conditions in which word identification occurs.

The race model predicts different results for the two kinds of stimulus presentation, as well as the two tasks. For "same" responses in the simultaneous presentation, first-letter-in-word matches should be faster than word matches. Moreover, for word matches, a word-frequency effect is predicted, but for first-letter-in-word matches, no such effect is expected. In the delayed presentation for word matches, a reduced frequency effect is predicted relative to the simultaneous condition, since the target item has already been identified prior to stimulus onset (Scarborough, Gerard, \& Cortese, 1979). Response time will be a function of one identification and comparison, rather than the two necessary with a simultaneous presentation. This will result in a reduced word vs. first-letter-in-word advantage, a reduced word-frequency effect, and faster responses to delayed relative to simultaneous presentations. For "different" responses, matches are more likely to be based on a letter level of analysis, and thus differences between conditions should be less likely.

\section{Method}

Design. The experiment consisted of a 2 (interval: simultaneous, delayed) by 2 (target condition: word, first letter in word) by 2 (word frequency: high, low) design for "same" and "different" responses.

Stimulus materials. The items were 196 word pairs, 20 of which constituted the practice trials. Of the remaining 176 word 
pairs (Appendix A), 120 required a "same" response and 56 required a "different" response. All words were five-letter onesyllable nouns typed in uppercase letters. For the 56 pairs requiring "different" responses, the words were identical except for the first letter (e.g., HOUSE-MOUSE). Both words within a pair were of the same frequency, high or low, as determined by the Kučera and Francis (1967) and Thorndike-Lorge (1944) word-frequency counts. Low-frequency words were those with a count of 10 and under; high-frequency words with seven exceptions had a count of 40 or over on one or both of the frequency counts. Each pair of high-frequency words had a corresponding word pair in the low-frequency word condition that started with the same initial letter.

For both simultaneous and delayed conditions, when the task was to match the first letter in a word, the target was always a word (e.g., TABLE-TABLE). As mentioned already, this differed from Johnson's (1975) procedure, in which the target consisted of a single letter (e.g., T-TABLE). The modification of Johnson's procedure was incorporated in an attempt to control for the part-whole controversy raised by both Massaro and Klitzke (1977) and McNeill and Lindig (1973).

Procedure. The word pairs were presented in a different random order to all participants, with half receiving the delayed condition first and half the simultaneous condition first. Within these conditions, half of the subjects received the word condition first and half the letter-in-word condition first. Within conditions, the presentation of high- and low-frequency words was randomized. The words within conditions were counterbalanced across participants.

Participants were required to respond "same" if in the word condition the two words were identical, or, in the first-letter-inword condition, if the first letters were the same; they were required to respond "different" if the relevant stimuli were different.

Words wìere presented in a three-field Electronics Development tachistoscope at a 10 -sec rate. In the simultaneous condition, a blank field was displayed for $2 \mathrm{sec}$, followed by the stimuli, which remained on for $2 \mathrm{sec}$. This was followed by a dark field for $6 \mathrm{sec}$. An automatic card changer controlled the presentation of the stimulus cards. In the delayed condition, a target word was displayed for $2 \mathrm{sec}$, followed for $1 \mathrm{sec}$ by a blank field, which in turn was followed by the stimulus word for $2 \mathrm{sec}$. A dark field was then displayed for $5 \mathrm{sec}$. In the simultaneous condition, the words appeared one above the other. The stimuli subtended a visual angle of $.66 \mathrm{deg}$ vertically and $1.13 \mathrm{deg}$ horizontally. In the delayed condition, the stimulus word occupied the same space in the visual field as the target word. In the delayed condition, the visual angle of both the target and stimulus words was $.23 \mathrm{deg}$ vertically and $1.13 \mathrm{deg}$ horizontally.

Reaction times were recorded from thumb-button response keys held by the participants. Reaction times were automatically recorded by timers with a tape printout. This also recorded the button pushed. Responses were recorded in milliseconds from onset of the stimuli in the simultaneous task and from onset of the stimulus word in the delayed task.

Subjects. The participants in this study were 16 Englishspeaking Deakin University students, 8 males and 8 females, with normal or corrected to normal vision.

\section{Results}

The results of the present experiment (see Table 1) were analyzed using the min $F^{\prime}$ test (Clark, 1973). Cutoff values were arbitrarily set at 300 and $1,500 \mathrm{msec}$ to minimize the effects of extremely short or long responses. This criterion affected less than $1 \%$ of the total responses. These items were not replaced in the analysis. The overall error rate for all conditions was
Table 1

Mean Response Time in Milliseconds to Words and First Letters in Words for Simultaneous and Delayed Conditions and Same-Different Responses in High- (HF) and Low-Frequency (LF) Words

\begin{tabular}{|c|c|c|c|c|}
\hline \multirow{3}{*}{$\begin{array}{c}\text { Stimulus } \\
\text { Display }\end{array}$} & \multicolumn{4}{|c|}{ Target Condition } \\
\hline & \multicolumn{2}{|c|}{ Words } & \multicolumn{2}{|c|}{ First Letters } \\
\hline & HF & $\mathrm{LF}$ & $\mathrm{HF}$ & $\mathrm{LF}$ \\
\hline & \multicolumn{4}{|c|}{ Same Responses } \\
\hline \multirow[t]{2}{*}{ Delayed } & $\begin{array}{l}729 \\
592\end{array}$ & $\begin{array}{l}793 \\
605\end{array}$ & $\begin{array}{l}661 \\
610\end{array}$ & $\begin{array}{l}669 \\
621\end{array}$ \\
\hline & \multicolumn{4}{|c|}{ Different Responses } \\
\hline $\begin{array}{l}\text { Simultaneous } \\
\text { Delayed }\end{array}$ & $\begin{array}{l}724 \\
632\end{array}$ & $\begin{array}{l}733 \\
619\end{array}$ & $\begin{array}{l}718 \\
680\end{array}$ & $\begin{array}{l}716 \\
640\end{array}$ \\
\hline
\end{tabular}

1.7\%. Response types were analyzed separately, in accordance with the race model of Chambers and Forster (1975), which predicts different patterns of results for "same" and "different" items.

For the "same" responses, analysis of variance demonstrated significant main effects of interval [min $\left.F^{\prime}(1,21)=20.07, p<.001\right]$, delayed responses being faster than simultaneous responses, and of frequency $\left[\min \mathrm{F}^{\prime}(1,26)=9.17, \mathrm{p}<.01\right]$, high-frequency items being responded to faster than low-frequency items. There was a significant Interval by Target Condition interaction $\left[\min F^{\prime}(1,24)=16.1, p<.001\right]$. This interaction is due to a first-letter-in-word match being faster than a word match in the simultaneous condition, and the word match being faster than the first-letter-in-word match in the delayed condition. A separate analysis revealed that, for the simultaneous task, there was a significant difference between the word and first-letterin-word conditions $\left[\min F^{\prime}(1,21)=7.78, p<.025\right]$, words taking longer to match than the first letter in the word. Also, in the word condition, high-frequency words were identified faster than low-frequency words [min $\left.F^{\prime}(1,23)=5.84, p<.025\right]$. There was no significant difference between high- and low-frequency words in the first-letter-in-word match $\left[\min F^{\prime}(1,22)<1\right]$. In the delayed task, there was no significant difference between response times for matching words and those for matching first letters in words, nor was there a significant frequency effect in either word or the first-letter-in-word condition.

For "different" responses, there was one significant main effect, that of interval $\left[\min F^{\prime}(1,20)=17.25\right.$, $p<.001]$; responses to the delayed task were faster than responses to the simultaneous task. There was neither a word vs. first-letter-in-word matching difference nor a word-frequency effect in either the simultaneous or delayed task for "different" responses.

\section{Discussion}

The main findings of the present experiment are inconsistent with predictions based on Johnson's (1975) 
hierarchical model of word identification. Words were not matched faster than the first letter in a word in any condition. With simultaneous presentations, letters in words were matched faster rather than slower than word matches. With delayed presentation, there was no significant difference between word and first-letter-inword matches. Furthermore, a word-frequency effect was not found in all conditions. In fact, a word-frequency effect occurred only for simultaneous word matches with "same" responses.

Johnson (1977) would argue that in the simultaneous condition of the present experiment, matches were based on a physical rather than a lexical level of analysis. Processing at a physical level, according to Johnson, would result in faster responses to the first letters in words, since less physical information was required to initiate a response. Johnson would attribute the wordfrequency effect found in the simultaneous word condition to the high-frequency items being more orthographically redundant than low-frequency items.

The results of the present experiment are also not entirely consistent with those reported by Marmurek (1977). Marmurek reported that in a delayed matching task, word matches were made faster than first-letter-inword matches. However, with a simultaneous presentation, the first letter in a word was matched faster than a word match. Marmurek concluded, as did Johnson (1977), that this reversal was due to different levels of analysis being responsible for the results from the delayed and simultaneous tasks. In a delayed task, Marmurek postulated that the target stimulus is identified and remains in working memory to be matched to the stimulus. For the first-letter-in-word match, a disintegration of the word is necessary to identify the letter, whereas for the word match, no disintegration is necessary. In the simultaneous task, Marmurek concluded that faster responses for first letters in words than for word matches are due to the comparison being based on the physical representation: There are fewer physical features to be compared in the first-letter-in-word conditions (e.g., T-TABLE) before a decision is made than in the word condition (e.g., TABLE-TABLE).

Marmurek's (1977) finding of faster matching times for words than for first letters in words with delayed presentation are inconsistent with both the predictions made by the race model and the results reported in the present experiment. The conflict in results warrants closer examination. Marmurek reports interactions of the target condition (word or first-letter-in-word match) with both interval (simultaneous or delay) and physical format (same- or mixed-case font). There is no further statistical analysis of the interactions. From an inspection of Marmurek's (1977, Figure 1) results, it appears that for delayed presentation, with "same" responses, the faster matching times for words than for first letters in words occur only for mixed-case items and not for same-case items. If this is so, then no direct conflict between the results reported by Marmurek and those for the present experiment exists. In both studies, there was apparently no difference for word and first-letter-inword matching times with delayed presentation when the stimuli were printed in the same case.

The finding of faster letter-in-word matches than word matches with a simultaneous presentation in the Marmurek (1977) study is consistent with the results of the present experiment. However, whereas Marmurek proposed that the matches are based on a physical representation, an alternative interpretation is that "same" responses for word matches are based on lexical information. Several studies have claimed that words are identified as words in a simultaneous matching task. Barron and Henderson (1977) base their interpretation on the finding that the first letter in a word was matched faster than the first letter in a legal nonword. Chambers and Forster (1975) base their similar conclusion on the finding that words were matched faster than legal nonwords and illegal nonwords. They also found that high-frequency words were matched faster than low-frequency words. To account for these results, Marmurek's model would need to explain the wordfrequency effects found by Chambers and Forster (1975) and in the present experiment, as well as the word-superiority effects reported by Barron and Henderson (1977), Barron and Pittenger (1974), and Chambers and Forster (1975) as being due to some factor other than lexical access.

One possible alternative explanation of these effects would be in terms of the orthographic structure of the items. Was there a variation in the orthographic structure of the high- and low-frequency words or of the words and nonwords in these studies? Studies by Mason (1975) and Massaro, Venezky, and Taylor (1979) suggest that the transitional probability (TP) of letter sequence is an important variable in word identification. The Chambers and Forster (1975) study indicated no correlation between the response times and the TPs of the bigrams or the trigrams of the letter sequences. Furthermore, Chambers (1976) reported no significant correlation between single-letter $\mathrm{TP}$ and response time in the Chambers and Forster data. A similar analysis of the items in the present experiment revealed significant correlations between matching times and the TPs of single letters and bigrams.

There was a significant difference in the TPs of the single letters and bigrams for high-and low-frequency words $[\mathrm{t}(29)=2.275, \mathrm{p}<.05$ (single letters) and $\mathrm{t}(29)=$ $2.125, \mathrm{p}<.05$ (bigrams)]. A partial-correlation analysis was performed on the single-letter and bigram TPs of the items in the present experiment with the response time data. When bigram TP was controlled, there was a significant correlation between single-letter $\mathrm{TP}$ and response time $[\mathrm{r}(56)=-.399, \mathrm{p}<.01]$. Conversely, when single-letter TP was controlled, no bigram TP correlation was present $[\mathrm{r}(56)=-.054, \mathrm{p}>.05]$. This 
post hoc analysis suggests that the word-frequency effect found in this experiment was primarily due to the single-letter TP of the items, rather than to the word-frequency of the items per se. A direct test of this possibility was performed in Experiment 2.

\section{EXPERIMENT 2}

Experiment 2 examined two issues arising from Experiment 1. First, it is possible that the word-frequency effect in Experiment 1 resulted from single-letter TP differences between high- and low-frequency words, and not to lexical status as such. Since orthography is defined, in part, by positional constraints on letters and letter clusters, the Mayzner and Tresselt (1965) norms provide a gross measure of orthographic regularity. Experiment 2 manipulated single-letter TP, while at the same time controlling for bigram TP. Furthermore, as in Experiment 1, the first letter across pairs of high- and low-frequency words were identical (e.g., BOARDBRINE), and within half the cases the first two letters in a pair were the same (e.g., CHAIN-CHUNK). Such controls should result in an elimination (or at least a reduction) in the word-frequency effect if such an effect is the result of orthography or letter frequency.

Second, a more powerful test of the word-frequency effect was undertaken. Although the delayed conditions of Experiment 1 did not support Marmurek's (1977) model, the results were in the right direction: a $17-\mathrm{msec}$ word-superiority effect and an 11-msec word-frequency effect. Given that one purpose of Experiment 2 was to test the word-frequency effect found in the simultaneous word condition of Experiment 1 and the lack of significant word-frequency effects in other conditions, a between-subjects design was utilized to increase the power of the results related to frequency within conditions. Power was increased by using all the items within a condition. This increased the sensitivity of the measures of word frequency and single-letter TP, which were within-subjects variables, at the sacrifice of the sensitivity of the between-subjects variables of target condition and interval. The subject population was also increased.

A 3-sec interval in the delayed condition was incorporated in the design of Experiment 2 to more closely approximate Marmurek's (1977) procedure.

The "different" items were constructed to provide a further test of the race model at the same time as increasing the pool of items. Half the "different" items differed by one letter only (e.g., BEAST-FEAST), and the remaining half differed on all the letters (e.g., BOUNDFRAME). Response times would be expected to be slower for similar "different" items, since for these items a letter level of analysis would indicate a "same" response when any but the first letter pair was identified. From the study by Chambers and Forster (1975), it seems unlikely that a letter level of analysis is invariably completed in a left-to-right fashion. The "different" items in Experiment 2 provide a further test of this interpretation.

\section{Method}

Experiment 2 manipulated word frequency and mean singleletter TP while controlling for bigram TP in both simultaneous and delayed word and letter in word-matching tasiks. For "same" responses, the experiment consisted of a 2 (interval: simultaneous, delayed) by 2 (target condition: word, first letter in word) by 2 (word frequency: high, low) by 2 (single-letter TP: high, low) design. Word frequency and single-letter TP were withinsubjects variables, and interval and target condition were between-subjects variables. For "different" responses, the experiment consisted of a 2 (interval: simultaneous, delayed) by 2 (target condition: word, first letter in word) by 2 (word frequency: high, low) by 2 (distractor type: similar, dissimilar) design. Word frequency and distractor type were within-subjects variables.

Stimulus materials and procedures were similar to those for Experiment 1. The items consisted of 170 word pairs, 10 of which constituted the practice trials. Of the remaining 160 word pairs (Appendix B), 80 required a "same" response and 80 a "different" response. Half of the items for both "same" and "different" response types were high-frequency words and half were low-frequency words. Within the high and low wordfrequency conditions for "same" responses, half the items had high single-letter TP counts and half had low single-letter TP counts. Words with a combined single-letter TP count of over 1,500 (mean $=1,818$ ) were classified as high single-letter TP items and those with a count of less than 1,500 (mean = $1,215)$ were classified as low single-letter TP items, as measured in the Mayzner and Tresselt (1965) tables. Items across conditions were matched for their initial letters. The same items were used for the simultaneous and delayed word and first-letter-inword conditions. The bigram TPs of the items were controlled as much as possible between the conditions of the experiment, given the restrictions placed on the selection of the items. Within high-frequency words, the mean bigram $\mathrm{TP}$ counts for high single-letter TP and low single-letter TP items were 221 and 200 , respectively. Within low-frequency words, the mean bigram TP counts for high single-letter TP and low single-letter TP were 168 and 172 , respectively. There was no significant difference between high and low single-letter TP counts within either highor low-frequency words $[\mathrm{t}(19)=.714, \mathrm{p}>.05 ; \mathrm{t}(19)=.174$, $\mathrm{p}>.05$, respectively]. There was no significant bigram TP difference between high- and low-frequency words with either high single-letter TP or low single-1etter TP $[t(19)=1.654$, $\mathrm{p}>.05 ; \mathrm{t}(19)=1.672, \mathrm{p}>.05$, respectively $]$. Overall, there was a significant bigram TP difference between high- and lowfrequency words $[t(39)=2.286, p<.05]$. Of the 80 "different" items, half differed by only the initial letter and half differed on all the letters. The "different" items were not controlled for bigram or single-letter TP.

The participants consisted of 104 English-speaking Deakin University students with normal or corrected to normal vision. Twenty-six subjects participated in each of the four betweensubjects tasks (simultaneous word, simultaneous first letter in word, delayed word, and delayed first letter in word).

\section{Results}

Cutoff values were set at $300 \mathrm{msec}$ for all conditions to minimize the effect of extremely fast responses. To minimize the effect of long response times, cutoff values were approximately double the mean response times for the individual conditions (simultaneous word, simultaneous first letter in word, delayed word, and 
delayed first letter in word). The cutoff affected $1.66 \%$, $1.06 \%, 1.32 \%$, and $2.24 \%$ of the responses, respectively. These items were not replaced in the analysis. The error rates for the four conditions were $2.45 \%, 2.17 \%, 1.95 \%$, and $1.87 \%$, respectively.

Analysis of variance for the "same" response (Table 2) revealed no significant main effect for single-letter TP. Single-letter TP did not interact with any other variable.

The data were collapsed, eliminating single-letter TP, and a further analysis of the "same" responses revealed three significant main effects. There was a significant interval effect $\left[\mathrm{min} \mathrm{F}^{\prime}(1,114)=21.97, \mathrm{p}<.001\right]$; responses to the delayed condition were faster than responses to the simultaneous condition. A significant target condition effect $\left[\mathrm{min} \mathrm{F}^{\prime}(1,110)=6.15, \mathrm{p}<.025\right]$ was produced by words being matched slower than first letters in words. A significant word-frequency effect was also observed $\left[\min \mathrm{F}^{\prime}(1,71)=8.5, \mathrm{p}<.01\right]$; highfrequency words were responded to faster than lowfrequency words. There were two significant secondorder interactions. The first was a significant interaction between interval and target condition $\left[\min F^{\prime}(1,110)=\right.$ $4.48, \mathrm{p}<.05$ ], which was attributed to words being matched relatively slower than first letters in words in the simultaneous rather than the delayed task. Also, there was a significant Frequency by Target Condition interaction $\left[\min F^{\prime}(1,109)=6.05, p<.025\right]$. Finally, there was a significant third-order interaction, that of Frequency by Target Condition by Interval [min $F^{\prime}(1,114)$ $=4.75, \mathrm{p}<.05]$. The last two interactions were generated by the simultaneous word condition within the experiment. Although high-frequency responses are equal to, or marginally faster than, low-frequency responses, in the simultaneous word condition the magnitude was greater. Furthermore, responses to the simultaneous word condition were slower than responses to the other three target conditions (simultaneous first letter, delayed word, and delayed first letter).

Separate analysis revealed that for the simultaneous task, there was a significant difference between the word and first-letter-in-word matching conditions $\left[\min \mathrm{F}^{\prime}(1,63)=15.11, \mathrm{p}<.001\right]$; words were matched slower than first letters in words. In the word condition, high-frequency words were responded to faster than

Table 2

Mean Response Time in Milliseconds to Words and First Letters in Words for Simultaneous and Delayed "Same" Conditions, High- (HF) and Low-Frequency (LF) Words, and High (HP) and Low (LP) Single-Letter Transitional Probability

\begin{tabular}{|c|c|c|c|c|c|c|c|c|}
\hline \multirow{4}{*}{$\begin{array}{l}\text { Stimulus } \\
\text { Display }\end{array}$} & \multicolumn{8}{|c|}{ Target Condition } \\
\hline & \multicolumn{4}{|c|}{ Words } & \multicolumn{4}{|c|}{ First Letters } \\
\hline & \multicolumn{2}{|c|}{ HF } & \multicolumn{2}{|c|}{ LF } & \multicolumn{2}{|c|}{$\mathrm{HF}$} & \multicolumn{2}{|c|}{ LF } \\
\hline & HP & LP & $\mathrm{HP}$ & LP & $\mathrm{HP}$ & LP & HP & LP \\
\hline Simultaneous & 664 & 661 & 704 & 709 & 601 & 607 & 598 & 609 \\
\hline Delayed & 555 & 556 & 572 & 576 & 550 & 552 & 564 & 568 \\
\hline
\end{tabular}

Table 3

Mean Response Time in Milliseconds to Words and First Letters in Words for Simultaneous and Delayed "Different" Conditions, Similar and Dissimilar Mismatch Conditions, and High- (HF) and Low-Frequency (LF) Words

\begin{tabular}{lllll}
\hline & \multicolumn{4}{c}{ Target Condition } \\
\cline { 2 - 5 } $\begin{array}{l}\text { Stimulus } \\
\text { Display }\end{array}$ & \multicolumn{2}{c}{ Words } & First Letters \\
\cline { 3 - 6 } \cline { 3 - 5 } & HF & LF & HF & LF \\
Similar & 679 & 689 & 642 & 652 \\
Dissimilar & 624 & 621 & 623 & 606 \\
& \multicolumn{5}{c}{ Simultaneous } \\
Similar & 583 & 594 & 612 & 615 \\
Dissimilar & 566 & 568 & 586 & 590 \\
\hline
\end{tabular}

low-frequency words $\left[\mathrm{min} \mathrm{F}^{\prime}(1,64)=10.84, \mathrm{p}<: 01\right]$. There was no significant word-frequency effect in the first-letter-in-word matching condition $\left[\min F^{\prime}(1,64)\right.$ $<1]$. In the delayed task, there was no difference in matching times for words vs. first letters in words $\left[\right.$ min $\left.F^{\prime}(1,63)<1\right]$. Within the word matching task, there was a word-frequency effect that was smaller than that in the simultaneous task, but significant [min $\left.F^{\prime}(1,63)=4.156, p<.05\right]$; high-frequency words were matched faster than low-frequency words. There were no significant frequency effects in the first-letter-in-word condition $\left[\min \mathrm{F}^{\prime}(1,64)=2.163, \mathrm{p}>.05\right]$.

For "different" responses (Table 3), there were two significant main effects, interval (simultaneous, delayed) and distractor type (similar, dissimilar). Responses to the simultaneous task were longer than responses to the delayed task $\left[\mathrm{min} \mathrm{F}^{\prime}(1,108)=10.3, \mathrm{p}<.01\right]$. Also, responses to similar target items took longer than responses to dissimilar target items $\left[\min F^{\prime}(1,29)=\right.$ $31.94, \mathrm{p}<.001]$. There was one second-order interaction, that of Distractor Type by Interval $\left[\mathrm{min} \mathrm{F}^{\prime}(1,59)\right.$ $=8.7, \mathrm{p}<.01]$. This is due to the similar items slowing down response time in the simultaneous task more than in the delayed task in relation to dissimilar items. In the simultaneous task, the difference between similar and dissimilar items was $54 \mathrm{msec}$, whereas in the delayed task, the difference was $29 \mathrm{msec}$. Although there was no main effect of target condition (word, first letter in word), in the simultaneous task for similar items, first letters in words were matched faster than words [min $\mathrm{F}^{\prime}$ $(1,132)=4.68, p<.05]$. For dissimilar items, there was no significant difference between words and first letters in words $\left[\mathrm{min} \mathrm{F}^{\prime}(1,114)<1\right]$. In the delayed task, there was no significant difference between words and first letters in words for either similar or dissimilar items $\left[\min \mathrm{F}^{\prime}(1,131)=2.6, \mathrm{p}>.05\right.$, and $\min \mathrm{F}^{\prime}(1,123)=2.19$, $\mathrm{p}>.05$, respectively].

\section{Discussion}

The results of Experiment 2, for both simultaneous and delayed conditions, do not support either Johnson's 
(1975) or Marmurek's (1977) model of word identification; rather, they are consistent with a race model. The present results suggest that the simultaneous word matching task is based on word identification rather than on a physical level of analysis, as proposed by Marmurek. In the simultaneous word condition, the word-frequency effect found in Experiment 1 and by Chambers and Forster (1975) was replicated. It is unlikely that this word-frequency effect can be attributed to orthography or to transitional probabilities of the stimuli, since in the present experiment, there was no significant single-letter TP difference between lists of words. There was also no significant correlation between bigram TP and response time $[\mathrm{r}(79)=.02, \mathrm{p}>.05]$. The fact that pairs of words across conditions were matched for the first letter in all cases and that 21 of the 40 highand low-frequency word pairs matched on their first two letters also argues against orthography as accounting for the large frequency effect.

The results of Experiments 1 and 2 provide support for the race model, whereas the Barron and Henderson (1977) finding that the first letter in a word is matched faster than the first letter in a legal nonword is inconsistent with a race model. The race model would predict no difference between processing the first letter in a word as opposed to a legal nonword, since both decisions would be based on a letter-level analysis of the initial letter. As the race model would predict that responding would be based on the letter level, it also contradicts Barron and Henderson's interpretation that in a letterin-word matching condition, the whole word is being processed. Experiment 3 was designed to replicate and extend the results of Barron and Henderson and to provide a further test of the race model.

\section{EXPERIMENT 3}

In Experiment 3 the interpretation proposed by Barron and Henderson (1977) of the results found in a simultaneous matching task was examined: The first letter in a word is processed faster than the first letter in a legal nonword due to the word being identified. If, in fact, the fast processing of the first letter in a word is due to word identification, a word-frequency effect would be predicted (a result opposite to the findings of Experiments 1 and 2). If, on the other hand, Chambers and Forster (1975) are correct and processing of simultaneous items can take place at a letter level, there should be no difference in processing the first letter in words, legal nonwords, and illegal nonwords.

\section{Method}

The experiment consisted of a 2 (case type: uppercase, lowercase) by 4 (letter string: high-frequency word, lowfrequency word, legal nonword, illegal nonword) design, with simultaneous presentation for both "same" and "different" responses. Letter case was a between-subjects variable and letter-string type was a within-subjects variable. Case was included in the design, so that the contribution of lowercase stimuli to Barron and Henderson's (1977) results could be evaluated. Most research in the area of word identification has used uppercase material in an attempt to eliminate shape as an uncontrolled variable. Barron and Henderson's results may have been affected by the use of lowercase stimuli.

Stimulus materials. The items were 140 letter-string pairs, 20 of which constituted the practice trials. Of the remaining 120 (Appendix C), half required a "same" response and half required a "different" response. All letter strings were five letters in length. Of the 60 letter strings requiring a "same" response, half consisted of one-syllable nouns. Of these 30 words, half were high frequency (a Kučera \& Francis, 1967, and Thorndike-Lorge, 1944 , count of over 40 ), and half were low frequency (10 or under). Words within a pair were equated for frequency. Of the remaining letter-string pairs, half were orthographically correct sequences (legal nonwords; e.g., BLOSH-BLOSH), and half were random letter strings (illegal nonwords; e.g., BHOSL-BHOSL). The letters constituting the legal and illegal nonwords came from the corresponding high- and low-frequency words. For the "different" responses, stimuli met the same criterion as "same" responses, except for the first letter in the pairs, which differed.

Apparatus and Procedure. The stimuli were typed and mounted on cards and displayed in a three-field Electronics Development tachistoscope. Stimuli were presented for $2 \mathrm{sec}$, with an interstimulus interval of $7.5 \mathrm{sec}$. The stimuli subtended a visual angle of $.66 \mathrm{deg}$ vertically and $1.13 \mathrm{deg}$ horizontally. Reaction times were recorded in milliseconds from onset of the stimulus. For half the participants, the stimuli were in uppercase; the same stimulus pairs in lowercase were used for the remaining participants.

Participants were required to respond "same" by pushing a red button if the first letter in the pairs was identical and to respond "different" by pushing a white button if the first letter in the two strings was not identical. The test trials were presented in three blocks of $\mathbf{4 0}$ stimuli. In other respects, the apparatus and procedure were identical to Experiment 1.

Subjects. The participants were 32 English-speaking Deakin University students, 16 males and 16 females, with normal or corrected to normal vision.

\section{Results}

The mean reaction times for both subjects and items were calculated. Cutoff values were arbitrarily set at 300 and $1,200 \mathrm{msec}$ to minimize the effect of extremely short or long responses. The cutoff affected $2.29 \%$ of the total responses. These items were not replaced in the analysis. The overall error rate for all conditions was $2.57 \%$. No further analysis of the error data was undertaken.

Analysis of variance demonstrated no significant difference between upper- and lowercase conditions [min $\left.F^{\prime}(1,33)<1\right]$ (see Table 4). Case did not interact with letter-string condition $\left[\min F^{\prime}(3,168)=1.06, p>.05\right]$. Since there was no significant effect of case, the data were collapsed for further analysis.

For "same" items, there was no significant difference between high- and low-frequency words $\left[\min \mathrm{F}^{\prime}(1,41)=\right.$ $2.25, \mathrm{p}>.05]$, nor was there a significant difference between high-frequency words and legal nonwords $\left[\min \mathrm{F}^{\prime}(1,41)=3.471, \mathrm{p}>.05\right]$. The only significant difference was between illegal nonwords and the other three conditions [illegal nonwords vs. high-frequency words, $\min \mathrm{F}^{\prime}(1,42)=37.4, \mathrm{p}<.001$; illegal nonwords vs. low-frequency words, $\min \mathrm{F}^{\prime}(1,42)=16.62, \mathrm{p}<.001$; 
Table 4

Mean Response Time in Milliseconds to First Letters in Words, Legal Nonwords, and Illegal Nonwords for Upper- and Lowercase Stimuli and Same-Different Responses

\begin{tabular}{ccccc}
\hline & \multicolumn{4}{c}{ Target Condition } \\
\cline { 2 - 5 } Stimulus & \multicolumn{3}{c}{ Words } & Nonwords \\
\cline { 2 - 5 } Display & HF & LF & Legal & Illegal \\
\hline & \multicolumn{4}{c}{ Same Responses } \\
Uppercase & 611 & 622 & 629 & 663 \\
Lowercase & 588 & 615 & 608 & 681 \\
& & Different Responses \\
Uppercase & 670 & 659 & 664 & 657 \\
Lowercase & 696 & 675 & 669 & 670 \\
\hline
\end{tabular}

Note $-H F=$ high frequency, $L F=$ low frequency.

illegal nonwords vs. legal nonwords, $\min \mathrm{F}^{\prime}(1,33)=$ $15.96, \mathrm{p}<.001]$. There were no significant differences between the four letter-string conditions for "different" responses.

\section{Discussion}

The results of the present experiment do not lend any support to Barron and Henderson's (1977) interpretation. No significant difference was found between matching times for the first letter in a word and first letter in a legal nonword. Further, there was no difference between high- and low-frequency words, an indication that the word as such was not being processed.

Experiments 1 and 2 demonstrated that in a simultaneous matching task, participants, when asked to identify the word, take significantly longer than when asked to identify only the first letter in the word. In the present experiment, participants apparently did not process the word when asked to process the first letter. This may not have been the case in the Barron and Henderson (1977) study, and that may explain why the results differ. It is possible that the participants were matching words rather than first letters in the Barron and Henderson experiment. Without the inclusion of a word matching task, the results cannot be definitively interpreted. However, a methodological difference may explain why Barron and Henderson's subjects might have used a word matching strategy. In the Barron and Henderson experiment, the stimuli were exposed for $500 \mathrm{msec}$ and response times were approximately $850 \mathrm{msec}, 350 \mathrm{msec}$ after the stimuli disappeared. It is possible that, to perform the task, participants had to store the stimulus in memory, and words were easier to store than legal nonwords, resulting in the demonstrated superiority of words over legal nonwords. In the design followed in Experiment 3, in which the stimulus was still present after the participant responded, the word-superiority effect may be absent when storing the stimulus is not necessary.

\section{GENERAL DISCUSSION}

The results of the present experiments support the predictions based on Chambers and Forster's (1975) race model of word identification rather than the hierarchical model proposed by Johnson (1975). In the simultaneous matching task for "same" responses, first letters in words were matched faster than words. This result, in conjunction with the word-frequency effect found in the word condition and the lack of a wordfrequency effect in the first-letter-in-word condition, indicates that, contrary to Johnson's model, a letter in the word can be analyzed independently of a word. The finding of a word-frequency effect in the simultaneous word matching condition supports the view that a simultaneous word match is not based on a physical level of analysis, but rather on a word level of analysis, which requires accessing lexical information held in memory. The results of Experiment 2 discount the view that the word-frequency effect is due to single-letter and bigram TP of stimuli used. The present findings indicate that, in a simultaneous matching task, when a word match is required, a word level of analysis controls the decision. However, when the task is to match the first letter in the word, the decision is controlled by a lower level of analysis (letter or letter cluster) that is faster than the word level of analysis. The findings are consistent with a model in which words, letter clusters, and letters are identified simultaneously. The results contradict Johnson's word-disintegration hypothesis and the need for a word to be identified before its component letters.

Both Johnson (1975) and Marmurek (1977) provide evidence that in a delayed matching task a wordsuperiority effect is present; matching a word to a word is performed faster than matching a letter to the first letter in a word. In the delayed matching task of Experiments 1 and 2, contrary to the findings of both Johnson and Marmurek, there was no significant difference between the word condition and the first-letter-in-word condition. The race model would predict that the delayed task would demonstrate a reduced or minimal first-letter matching superiority over word matching relative to the simultaneous task due to recency priming; there should be faster responses to a stimulus as a result of recent identification of that item. The lack of a lettersuperiority effect that was observed in the delayed task could be due to the increased probability that response times based on word and letter levels of analysis would be more similar with the reduced number of identifications and comparisons necessary and that either level of analysis would be sufficient for an appropriate response from the pool of items used.

The stimuli in the three studies may account partly for the differing results. The increased time to respond to the first-letter-in-word matching condition relative to the word matching condition in both the Johnson (1975) and Marmurek (1977) studies may be due to a disruption in the system caused by the mismatch between the target and the stimulus in this condition (e.g., T-TABLE). In the present experiments, in which no mismatch occurred between the target and stimulus, 
the word-superiority effect disappears. The differing findings of the three studies suggest that stimuli (e.g., words) can be analyzed at different levels and that these levels will be reflected in the nature of the task and the stimuli used.

It should be noted that Johnson's (1975) results were based on a combined analysis of response type that may provide an alternative interpretation of the differing results. Chambers and Forster (1975) proposed that identifications in "same" and "different" judgments are part of the same process; however, they point out that any direct comparison of the same-different response types is unwarranted. For "same" responses, when the task is to identify the whole unit, all letters need to be considered, whereas, for "different" responses, a decision is possible as soon as two conflicting units are identified. This could occur earlier than the identification of all letters in the case of analysis at the letter or letter-cluster levels. Additionally, for "different" judgments, the decision maker is faced with conflicting information not present for "same" judgments. Some letter pairs within a word stimulus will suggest a "same" response, whereas other pairs will point to a "different" response. The resolution of such a conflict may add time to the decision process for "different" judgments.

Johnson (1975) reported a significant interaction between response type and conditions. An examination of the "same" responses in his results revealed that words (e.g., TABLE-TABLE) were matched $25 \mathrm{msec}$ faster than first letters in words (e.g., T-TABLE) and that, contrary to the model, words were matched 21 msec slower than letters (e.g., T.T). For "different" responses, words were matched 49 msec faster than first letters in words and $2 \mathrm{msec}$ slower than letters. The overall analysis indicated that words were matched faster than first letters in words, but no faster than letters. If the 25-msec difference between word and first-letter-inword matches was significant for "same" items, Johnson's contention that words are identified before the component letters would be supported; however, using the same set of data, the contention that word and letter matches are equal might be rejected if the $21-\mathrm{msec}$ difference was statistically significant. If the $25-\mathrm{msec}$ difference found by Johnson for word and first-letterin-word matches for "same" items was not significant, then Johnson's hierarchical model rests on evidence for "different" items only. The possible confounding in Johnson's data points to the necessity of reporting same-different results separately. Johnson's contention that, in a delayed task, letters in words take longer to identify than words is not supported by the results of either the "same" or the "different" responses in Experiment 1 or 2, although the data for "different" responses do demonstrate a trend toward a word-superiority effect in a delayed task. This trend supports the possibility that Johnson's word-superiority effect holds only for "different" items with delayed presentation conditions.
The word-frequency effects for "same" responses found in both the simultaneous and delayed word matching tasks support the race model. Both Experiments 1 and 2 demonstrated a large frequency effect in the simultaneous word matching condition $(64 \mathrm{msec}$ and 45 msec, respectively) relative to the delayed word matching condition (13 $\mathrm{msec}$ and $19 \mathrm{msec}$, respectively, the latter being significant). The reduced wordfrequency effect for "same" responses in the delayed word matching condition of Experiment 2 is in keeping with a race model that would attribute the attenuated frequency effect to recency priming. Swift (Note 3) reported a reduced word-frequency effect in a lexical decision task when the target and stimulus were presented sequentially. Scarborough et al. (1979) also reported a reduced frequency effect when the item had been seen previously. There was no word-frequency effect for either the simultaneous or the delayed firstletter-in-word condition in Experiment 1 or 2 . The presence of a frequency effect in both the simultaneous and delayed word matching conditions and the lack of such effects in the first-letter-in-word matching conditions provides extra support for the contention that two levels of processing occur simultaneously rather than a hierarchical model in which the word is identified before the component letters.

The lack of a word-frequency effect in the first-letterin-word matching task for "same" responses in Experiment 3 replicated the results of Experiments 1 and 2 for a simultaneous matching task. In Experiment 3, in which orthography was manipulated, there was no difference between first letters in words and first letters in legal nonwords, but there was an effect of orthography; the first letters in illegal nonwords took longer than both the first letters in words and the first letters in legal nonwords.

The finding of an orthographic effect for "same" responses in a first-letter matching task (Experiment 3) constitutes a conundrum. It has been assumed so far that when the task is to match a first letter, a letter level of analysis determines the decision. An alternative interpretation of the finding is that a letter-cluster level of analysis often determines the "same" response when first letters are to be matched, giving an advantage to words and legal nonwords. In Experiment 3, in which the "different" items differed by only one letter (the first letter) from "same" items, a letter-cluster level of analysis would be the most efficient strategy for a correct "same" response. This is assuming that processing is not sequential, that is, that the subject does not always analyze in a left-to-right fashion, as suggested by the results of Experiment 2 for "different" items (see below). Using a five-letter word as an example and assuming that the word has three letter clusters, the number of identifications and comparisons necessary to make a "same" response at a letter level would be a proportion of the five possible identifications and com. 
parisons, whereas, at a letter-cluster level, the response times would be a function of the three possible identifications and comparisons. With suitable identification and comparison times for letters and letter clusters, this could result, on average, in faster decision times at a letter-cluster level of analysis.

For "different" items in Experiment 3 there was no word-nonword effect, nor was there a difference between legal and illegal nonwords. For this task, a letter level of analysis appears to be able to determine a correct response on the basis of the inconsistent firstletter mismatch, before the letter-cluster level has completed its analysis, eliminating orthographic effects.

Chambers and Forster (1975) reported that for "different" items illegal nonwords took longer than either words or legal nonwords when the items differed only by one letter, a result similar to the "same" responses of Experiment 3. Since in their task participants were required to respond "same" or "different" on the basis of the whole letter string as opposed to the first letter, it is possible that the letter-cluster level determined responses to their "different" items when only one letter differed, resulting in an orthographic effect for such items. For those items that differed on all the letters, the orthographic effect disappeared, indicating that when no conflicting information is present, the letter level of analysis is the fastest for "different" items.

In Experiment 2 of the present study, for "different" responses, the word matching condition for similar mismatches was the same as that in the Chambers and Forster (1975) study. Since they found an orthographic effect in their "different" items when the task was to match words and the items differed only on one letter, it is likely that in Experiment 2 for similar word mismatches, a letter-cluster level of analysis determined the decision. This would account for the faster response times to the first letters in words than on word matching for similar "different" items, since for first-letter-inword matches, identification at a letter level would be sufficient. This interpretation is consistent with the results for the "different" items in Experiment 3, in which no orthographic effect was present when the task was to match on the basis of the first letter. In Experiment 2, when the "different" items differed on all the letters, there was no word/first-letter-in-word difference, indicating that a letter level of analysis determined the decision. This result is consistent with the Chambers and Forster data, in which in a word matching task for different items, when all the letters differed, no orthographic effects were present.

The results for "different" responses in Experiment 2 with a simultaneous presentation support the view that a letter level of analysis does not necessarily proceed serially from left to right. In the first-letter-in-word condition, responses were slower when the items had all but one letter in common (e.g., BEAST-FEAST) than when all the letters differed. This result indicates that a decision is not always based on the identification of the first letter pair. The faster responses to the first-letter dissimilar mismatch, as opposed to the first-letter similar mismatch, indicate that although attention can be focused on the first letter pair, this is not done consistently. Thus the nature of the difference in the items and the task are critical in determining which level of analysis is used and, in the present case, whether the subject focuses on a particular letter position.

In summary, the experiments reported here cast doubt on the idea of the word being the primary unit of identification in matching tasks. Participants do not have to identify the word first when asked to make decisions based only on the first letter in the word. It would appear that the different results obtained in experiments examining words and letters in words may be due to the items used and the task demands. These results provide no support for a model of word identification that assumes that the whole word is interpreted before the individual letters; rather, they support a model in which words and letters in words are identified simultaneously.

\section{REFERENCE NOTES}

1. Johnson, N. F. The processing of letters in word identification. Paper presented at the symposium on Issues in Word Recognition, American Psychological Association, San Francisco, 1977.

2. Umansky, J. A. Word identification: Unit or parallel process? Paper presented at the 4th Experimental Psychology Conference, Newcastle, Australia, May 1977.

3. Swift, D. Word-frequency, word-length, and same-different effects with a nonsimultaneous matching task. Paper presented at the 48th meeting of the Eastern Psychological Association, Boston, April 1977.

\section{REFERENCES}

Barron, R. W., \& Henderson, L. The effects of lexical and semantic information on same-different visual comparisons of words. Memory \& Cognition, 1977, 5, 566-579.

Barron, R. W., \& Pittenger, J. B. The effect of orthographic structure and lexical meaning on same-different judgments. Quarterly Journal of Experimental Psychology, 1974, 26, 566-581.

Cattell, J. M. The time it takes to see and name objects. Mind, $1886,11,63-65$.

CHAMBERS, S. M. The use of visual information in word recognition. Unpublished doctoral dissertation, Monash University, 1976.

Chambers, S. M., \& Forster, K. L. Evidence for lexical access in a simultaneous matching task. Memory \& Cognition, 1975, 3, 549-559.

Clark, H. H. The language-as-fixed-effect fallacy: A critique of language statistics in psychological research. Journal of Verbal Learning and Verbal Behavior, 1973, 12, 135-139.

Forster, K. L., \& Chambers, S. M. Lexical access and naming time. Journal of Verbal Learning and Verbal Behavior, 1973, $12,627-635$.

Johnson, N. F. On the function of letters in word identification: Some data and a preliminary model. Journal of Verbal Learning and Verbal Behavior, 1975, 14, 17-29.

JoHNSON. N. F. A pattern unit model of word perception. In D. LaBerge \& J. Samuels (Eds.), Basic processes in reading: 
Perception and comprehension. Hillsdale, N.J: Erlbaum, 1977.

Kučera, H., \& ERincis, W. N. Computational analysis of present-day American English. Providence, R.I: Brown University Press, 1967.

Marmure $\mathrm{K}, \mathrm{H}$. Processing letters in words at different levels. Memory \& Cognition, 1977, 5, 67-72.

Mason, M. Reading ability and letter search time: Effects of orthographic structure defined by single-letter positional frequency. Journal of Experimental Psychology: General, 1975, 104, 146-166.

Massaro, D. W., \& Klitzke, D. Letters are functional in word identification. Memory \& Cognition, 1977, 5, 292-298.

Massaro, D. W., Venezky, R. L., \& Taylor, G. A. Orthographic regularity, positional frequency, and visual processing of letter strings. Journal of Experimental Psychology: General, $1979,108,107-124$.

Mayzner, M. S., \& Tresselt, M. E. Tables of single-letter and digram frequency counts for various word-length and letterposition combinations. Psychonomic Monograph Supplements, 1965, 1, 13-32.

Mayzner, M. S., Tresselt, M. E., \& Wolin, B. R. Tables of trigram frequency counts for various word-length and letterposition combinations. Psychonomic Monograph Supplements, $1965,1,33-78$.

McNeill, D., \& Lindig, K. The perceptual reality of phonemes, syllables, words and sentences. Journal of Verbal Learning and Verbal Behavior, 1973, 12, 419-430.

Nakatani, L. H. On the evaluation of models for the word frequency effect. Psychological Review, 1973, 80, 195-202.

Pillsaury, W. A study of apperception. American Journal of Psychology, 1897, 8, 315-393.

Rubenstein, H., Lewis, S. S., \& Rubenstein, M. A. Evidence for phonemic recoding in visual word recognition. Journal of Verbal Learning and Verbal Behavior, 1971, 10, 645-657.

Scarborough, D. L., Cortese, C., \& Scarborough, H. S. Frequency and repetition effects in lexical memory. Journal of Experimental Psychology: Human Perception and Performance, 1977, 3, 1-17.

Scarborough, D. L., Gerard, L., \& Cortese, C. Accessing lexical memory: The transfer of word repetition effects across task and modality. Memory \& Cognition, 1979, 7, 3-12.

Solomon, R. L., \& Postman, L. Frequency of usage as a determinant of recognition thresholds for words. Journal of Experimental Psychology, 1952, 43, 195-201.

Thorndike, E. L., \& LorGE, I. The teacher's word book of 30,000 words. New York: Columbia University Teachers College, Bureau of Publications, 1944.

(Received for publication September 13, 1979; revision accepted February 15, 1980.)

Appendix A

Items Used in Experiment 1

\begin{tabular}{|c|c|c|c|c|c|c|c|}
\hline \multicolumn{8}{|c|}{ "Same" Items } \\
\hline \multicolumn{4}{|c|}{ High-Frequency Words } & \multicolumn{4}{|c|}{ Low-Frequency Words } \\
\hline BLOCK & BLACK & BOARD & BUILD & BATHE & BRINE & BATCH & BLAZE \\
\hline BIRTH & BREAD & BROAD & BENCH & BIRCH & BIGHT & BADGE & BERTH \\
\hline CLOTH & COURT & CHEST & CLAIM & CLEAT & CHIVE & CRYPT & CHUNK \\
\hline CHAIR & CLASS & CHILD & CHAIN & CHUTE & CRUST & CRUMB & CACHE \\
\hline DRILL & DEATH & DANCE & DRUNK & DIRGE & DWARF & DRONE & DROLL \\
\hline FRONT & FLOOR & FLOUR & FRUIT & FARCE & FLUTE & FILTH & FROCK \\
\hline GREEN & GLASS & GRASS & GRAIN & GNOME & GRIST & GHOUL & GULCH \\
\hline GUESS & GROUP & GUARD & GUEST & GAUZE & GRATE & GUILD & GLADE \\
\hline MARCH & MONTH & MIGHT & MOUNT & MAUVE & MAIZE & MOULD & MULCH \\
\hline PRICE & PIECE & PLANT & PHONE & PRANK & PULSE & PERCH & PIQUE \\
\hline PLACE & PLANE & PEACE & PHASE & PLUMB & PRONG & PEARL & PLASM \\
\hline SPACE & SMOKE & SCORE & SHAPE & SHAWL & STUMP & STALK & SLANT \\
\hline SLEEP & STORE & STAND & SMILE & SHACK & SWAMP & SALVE & SQUAB \\
\hline TRUCK & THING & THREE & TRAIL & TORCH & TRUCE & THIGH & TAUNT \\
\hline \multirow{2}{*}{\multicolumn{2}{|c|}{ WORLD }} & WHEEL & WOUND & WHARF & WINCH & WENCH & WEAVE \\
\hline & & & "Diffe & Items & & & \\
\hline \multicolumn{4}{|c|}{ High-Frequency Words } & \multicolumn{4}{|c|}{ Low-Frequency Words } \\
\hline \multirow{14}{*}{\multicolumn{2}{|c|}{$\begin{array}{l}\text { BLAME/FLAME } \\
\text { BEACH/TEACH } \\
\text { DRAFT/CRAFT } \\
\text { CRIME/PRIME } \\
\text { TOAST/COAST } \\
\text { GRADE/TRADE } \\
\text { PAINT/FAINT } \\
\text { BLOOD/FLOOD } \\
\text { BRAIN/TRAIN } \\
\text { DREAM/CREAM } \\
\text { CAUSE/PAUSE } \\
\text { TRACK/CRACK } \\
\text { GREAT/TREAT } \\
\text { POUND/FOUND }\end{array}$}} & \multicolumn{2}{|c|}{ MOUTH/SOUTH } & \multicolumn{2}{|c|}{ BEAST/FEAST } & \multicolumn{2}{|c|}{ MOOSE/NOOSE } \\
\hline & & \multicolumn{2}{|c|}{ WATCH/MATCH } & \multicolumn{2}{|c|}{ BRASH/TRASH } & \multicolumn{2}{|c|}{ WHALE/SHALE } \\
\hline & & \multicolumn{2}{|c|}{ FIGHT/LIGHT } & \multicolumn{2}{|c|}{ DOUGH/COUGH } & \multicolumn{2}{|c|}{ LATHE/BATHE } \\
\hline & & \multicolumn{2}{|c|}{ NIGHT/RIGHT } & \multicolumn{2}{|c|}{ COUCH/POUCH } & \multicolumn{2}{|c|}{ NYMPH/LYMPH } \\
\hline & & \multicolumn{2}{|c|}{ POINT/JOINT } & \multicolumn{2}{|c|}{ TROUP/CROUP } & \multicolumn{2}{|c|}{ FAULT/VAULT } \\
\hline & & \multicolumn{2}{|c|}{ SOUND/ROUND } & \multicolumn{2}{|c|}{ GRILL/TRILL } & \multicolumn{2}{|c|}{ SLUMP/CLUMP } \\
\hline & & \multicolumn{2}{|c|}{ NORTH/WORTH } & \multicolumn{2}{|c|}{ PLANK/FLANK } & \multicolumn{2}{|c|}{ FLAKE/SLAKE } \\
\hline & & \multicolumn{2}{|c|}{ WASTE/HASTE } & BLA & FLARE & WED & EDEE \\
\hline & & CRO & ROWN & BRI & RIBE & BRO & ROOK \\
\hline & & PRID & IDE & DRA & CRAWL & PUNC & $\mathrm{JNCH}$ \\
\hline & & BRA & RAVE & CUR & URSE & DRA & $\mathrm{APE}$ \\
\hline & & DRE & ESS & TRA & CRAMP & GIRT & RTH \\
\hline & & HOU & DUSE & GRI & RIPE & FLIN & NT \\
\hline & & FIEL & ILD & PIN & INCH & SWIN & INE \\
\hline
\end{tabular}


Appendix B

Items Used in Experiment 2 With the Mean Response Times in Milliseconds for Each Item for the Simultaneous Word (SW), Simultaneous Letter-in-Word (SL), Delayed Word (DW), and Delayed Letter-in-Word (DL) Conditions

"Same" Items

High-Frequency Words

High Single-Letter TP SW SL DW DL

Low Single-Letter TP

SW SL DW DL

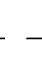

Low-Frequency Words

High Single-Letter TP Low Single-Letter TP

SW SL DW DL

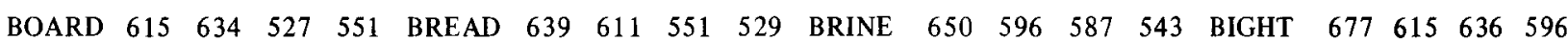
$\begin{array}{lllllllllllllllllllll}\text { BUILD } & 626 & 550 & 534 & 526 & \text { BENCH } & 710 & 655 & 603 & 613 & \text { BEIGE } & 700 & 544 & 580 & 550 & \text { BIRCH } & 652 & 573 & 571 & 565\end{array}$ $\begin{array}{llllllllllllllllllllll}\text { COURT } & 712 & 658 & 539 & 588 & \text { CLOTH } & 611 & 577 & 548 & 579 & \text { CHIVE } & 683 & 514 & 557 & 491 & \text { CLEAT } & 745 & 509.607 & 566\end{array}$ $\begin{array}{llllllllllllllllllll}\text { CHAIN } & 656 & 581 & 581 & 522 & \text { CLAIM } & 646 & 618 & 551 & 493 & \text { CHUNK } & 586 & 560 & 566 & 583 & \text { CACHE } & 769 & 587 & 512 & 519\end{array}$ $\begin{array}{llllllllllllllllllll}\text { CHAIR } & 638 & 561 & 551 & 536 & \text { CROWD } & 628 & 627 & 536 & 538 & \text { CHIDE } & 711 & 598 & 557 & 577 & \text { CRUMB } & 745 & 565 & 533 & 579\end{array}$ $\begin{array}{llllllllllllllllllllllll}\text { CHEST } & 685 & 565 & 505 & 577 & \text { CATCH } & 615 & 582 & 533 & 509 & \text { CHUTE } & 693 & 571 & 536 & 560 & \text { CRUST } & 671 & 627 & 548 & 592\end{array}$ $\begin{array}{lllllllllllllllllllll}\text { DRESS } & 677 & 596 & 549 & 528 & \text { DEATH } & 629 & 608 & 521 & 566 & \text { DRONE } & 713 & 641 & 569 & 559 & \text { DROLL } & 641 & 605 & 584 & 567\end{array}$ $\begin{array}{llllllllllllllllllllllll}\text { FAULT } & 634 & 612 & 603 & 554 & \text { FLOOR } & 624 & 639 & 535 & 554 & \text { FARCE } & 830 & 623 & 611 & 616 & \text { FILTH } & 693 & 609 & 570 & 590\end{array}$ $\begin{array}{lllllllllllllllllllllll}\text { FRONT } & 623 & 624 & 544 & 538 & \text { FLOUR } & 624 & 655 & 560 & 594 & \text { FLINT } & 662 & 601 & 545 & 570 & \text { FROCK } & 769 & 695 & 582 & 529\end{array}$ $\begin{array}{lllllllllllllllllllllll}\text { GRASS } & 632 & 579 & 582 & 554 & \text { GREEN } & 586 & 585 & 551 & 546 & \text { GREED } & 735 & 628 & 572 & 563 & \text { GULCH } & 749 & 661 & 608 & 589\end{array}$ $\begin{array}{llllllllllllllllllllllllll}\text { GUESS } & 685 & 632 & 543 & 551 & \text { GROUP } & 650 & 586 & 546 & 561 & \text { GRATE } & 736 & 633 & 605 & 573 & \text { GHOUL } & 815 & 708 & 586 & 531\end{array}$ $\begin{array}{llllllllllllllllllllll}\text { MOUNT } & 659 & 582 & 518 & 537 & \text { MIGHT } & 729 & 686 & 558 & 551 & \text { MAIZE } & 713 & 630 & 532 & 588 & \text { MULCH } & 728 & 620 & 581 & 577\end{array}$ $\begin{array}{lllllllllllllllllllllll}\text { NOISE } & 609 & 569 & 501 & 500 & \text { NORTH } & 639 & 592 & 504 & 563 & \text { NOOSE } & 646 & 629 & 568 & 524 & \text { NOTCH } & 689 & 615 & 542 & 569\end{array}$ $\begin{array}{lllllllllllllllllllllll}\text { PLANE } & 722 & 708 & 566 & 624 & \text { PLANT } & 639 & 633 & 544 & 581 & \text { PRUNE } & 809 & 654 & 537 & 613 & \text { PEARL } & 633 & 598 & 523 & 529\end{array}$ $\begin{array}{lllllllllllllllllllllll}\text { PIECE } & 749 & 576 & 605 & 565 & \text { PORCH } & 758 & 608 & 538 & 563 & \text { PROSE } & 726 & 638 & 573 & 588 & \text { PRONG } & 734 & 674 & 592 & 565\end{array}$ $\begin{array}{llllllllllllllllllllllll}\text { SLEEP } & 608 & 585 & 512 & 505 & \text { STOCK } & 677 & 630 & 557 & 581 & \text { SHAWL } & 688 & 577 & 577 & 524 & \text { STUMP } & 596 & 560 & 610 & 566\end{array}$ $\begin{array}{lllllllllllllllllllllll}\text { SMOKE } & 645 & 602 & 563 & 543 & \text { STICK } & 674 & 567 & 607 & 521 & \text { SALVE } & 779 & 613 & 651 & 566 & \text { STALK } & 670 & 614 & 556 & 588\end{array}$ $\begin{array}{lllllllllllllllllllllll}\text { THREW } & 682 & 631 & 610 & 561 & \text { TRUCK } & 644 & 588 & 575 & 519 & \text { TAUNT } & 651 & 569 & 562 & 523 & \text { TRUMP } & 748 & 608 & 562 & 604\end{array}$ $\begin{array}{lllllllllllllllllllll}\text { THREE } & 604 & 570 & 540 & 564 & \text { TRAIL } & 635 & 605 & 624 & 515 & \text { TWEED } & 664 & 559 & 522 & 553 & \text { THUMB } & 601 & 603 & 568 & 538\end{array}$ $\begin{array}{lllllllllllllllllllll}\text { WORTH } & 646 & 619 & 576 & 604 & \text { WATCH } & 682 & 565 & 563 & 570 & \text { WEAVE } & 684 & 592 & 595 & 548 & \text { WINCH } & 663 & 571 & 599 & 602\end{array}$

"Different" Items: Similar

\begin{tabular}{|c|c|c|c|c|c|c|c|c|c|}
\hline \multicolumn{5}{|c|}{ High-Frequency Words } & \multicolumn{5}{|c|}{ Low-Frequency Words } \\
\hline & SW & $\mathrm{SL}$ & DW & $\mathrm{DL}$ & & SW & SL & DW & $\mathrm{DL}$ \\
\hline BLAME/FLAME & 639 & 650 & 610 & 622 & BEAST/FEAST & 721 & 691 & 547 & 632 \\
\hline $\mathrm{BEACH} / \mathrm{TEACH}$ & 640 & 560 & 540 & 602 & BRASH/TRASH & 650 & 657 & 583 & 654 \\
\hline CRIME/PRIME & 670 & 574 & 554 & 593 & COUCH/POUCH & 620 & 597 & 601 & 668 \\
\hline COAST/TOAST & 621 & 596 & 582 & 657 & CRAMP/TRAMP & 686 & 570 & 551 & 581 \\
\hline CROWN/BROWN & 664 & 602 & 588 & 582 & CROOK/BROOK & 618 & 635 & 553 & 626 \\
\hline CREAM/DREAM & 738 & 652 & 578 & 666 & CRAWL/DRAWL & 714 & 622 & 556 & 601 \\
\hline DRAFT/CRAFT & 686 & 647 & 627 & 648 & DOUGH/COUGH & 661 & 662 & 598 & 635 \\
\hline FAINT/PAINT & 825 & 693 & 567 & 632 & FLANK/PLANK & 775 & 772 & 618 & 576 \\
\hline FLOOD/BLOOD & 709 & 671 & 585 & 574 & FLARE/BLARE & 672 & 706 & 630 & 636 \\
\hline GRADE/TRADE & 602 & 619 & 578 & 620 & GRILL/TRILL & 657 & 632 & 594 & 636 \\
\hline GLASS/CLASS & 819 & 749 & 735 & 747 & GLOVE/CLOVE & 891 & 764 & 738 & 667 \\
\hline MOUSE/HOUSE & 738 & 715 & 647 & 606 & MARSH/HARSH & 771 & 707 & 613 & 593 \\
\hline NIGHT/LIGHT & 678 & 641 & 569 & 625 & NYMPH/LYMPH & 641 & 602 & 648 & 643 \\
\hline POUND/FOUND & 772 & 772 & 646 & 698 & PINCH/FINCH & 778 & 691 & 631 & 658 \\
\hline PAUSE/CAUSE & 671 & 610 & 583 & 582 & PURSE/CURSE & 640 & 587 & 571 & 592 \\
\hline SIGHT/FIGHT & 674 & 631 & 546 & 528 & SLAKE/FLAKE & 650 & 646 & 588 & 596 \\
\hline SLASH/FLASH & 698 & 650 & 553 & 597 & SABLE/FABLE & 658 & 631 & 599 & 591 \\
\hline TREAT/GREAT & 610 & 600 & 589 & 626 & TRIPE/GRIPE & 649 & 646 & 598 & 572 \\
\hline TRACK/CRACK & 580 & 631 & 571 & 580 & TROUP/CROUP & 654 & 595 & 593 & 597 \\
\hline WASTE/HASTE & 675 & 684 & 611 & 654 & WEDGE/HEDGE & 797 & 654 & 577 & 649 \\
\hline
\end{tabular}

"Different" Items: Dissimilar

\begin{tabular}{|c|c|c|c|c|c|c|c|c|c|}
\hline \multicolumn{5}{|c|}{ High-Frequency Words } & \multicolumn{5}{|c|}{ Low-Frequency Words } \\
\hline & SW & SL & DW & $\mathrm{DL}$ & & SW & SL & DW & $\mathrm{DL}$ \\
\hline BOUND/FRAME & 635 & 620 & 599 & 570 & BATHE/FLASK & 635 & 630 & 606 & 627 \\
\hline BRAVE/TEETH & 606 & 593 & 564 & 555 & BLAZE/THIEF & 651 & 625 & 581 & 621 \\
\hline CHEER/PRICE & 655 & 624 & 587 & 638 & CHESS/PERCH & 618 & 606 & 577 & 537 \\
\hline CLEAR/TRICK & 582 & 607 & 532 & 601 & CRYPT/TWINE & 593 & 582 & 570 & 573 \\
\hline CHECK/BLOCK & 620 & 644 & 581 & 599 & CROCK/BRAKE & 585 & 616 & 538 & 600 \\
\hline CHIEF/DRINK & 593 & 604 & 563 & 636 & CHALK/DEUCE & 588 & 580 & 581 & 592 \\
\hline DRUNK/CHILD & 570 & 635 & 548 & 567 & DRAPE/CLOUT & 607 & 588 & 542 & 536 \\
\hline
\end{tabular}


Appendix B (Continued)

"Different" Items: Dissimilar

\begin{tabular}{|c|c|c|c|c|c|c|c|c|c|}
\hline \multicolumn{5}{|c|}{ High-Frequency Words } & \multicolumn{5}{|c|}{ Low-Frequency Words } \\
\hline & SW & SL & DW & DL & & SW & SL & DW & DL \\
\hline FIELD/PRESS & 644 & 728 & 564 & 558 & FLECK/PULSE & 692 & 657 & 625 & 599 \\
\hline FLESH/BROAD & 590 & 638 & 577 & 590 & FINCH/BADGE & 667 & 618 & 561 & 601 \\
\hline GRANT/THEME & 657 & 604 & 634 & 601 & GRIST/THORN & 572 & 534 & 550 & 571 \\
\hline GRAVE/CLERK & 714 & 692 & 604 & 653 & GRIME/CLOWN & 685 & 714 & 584 & 627 \\
\hline MOUTH/HONEY & 763 & 641 & 574 & 606 & MUNCH/HEATH & 670 & 649 & 580 & 624 \\
\hline NURSE/LEAVE & 654 & 590 & 589 & 594 & NEIGH/LATHE & 641 & 545 & 559 & 600 \\
\hline PHONE/FLOAT & 611 & 627 & 571 & 570 & PLUMB/FROTH & 656 & 631 & 565 & 601 \\
\hline PLACE/COACH & 598 & 617 & 606 & 594 & PIQUE/CLUMP & 591 & 571 & 566 & 561 \\
\hline SWEET/FLASH & 608 & 604 & 521 & 540 & SHAWL/FORGE & 612 & 567 & 549 & 592 \\
\hline SHAPE/FLUTE & 580 & 603 & 566 & 572 & SLANT/FLASK & 612 & 564 & 557 & 561 \\
\hline THANK/GREET & 571 & 579 & 534 & 587 & TREAD/GAUZE & 599 & 540 & 569 & 658 \\
\hline THICK/COURT & 612 & 582 & 553 & 616 & TORCH/CLOUT & 609 & 563 & 580 & 610 \\
\hline WORLD/HEART & 588 & 638 & 536 & 571 & WHARF/HORDE & 612 & 605 & 589 & 598 \\
\hline
\end{tabular}

Appendix C

Items Used in Experiment 3 Together With the Mean Response Times in Milliseconds for Each Item

\begin{tabular}{|c|c|c|c|c|c|c|c|}
\hline \multicolumn{8}{|c|}{ "Same" Items } \\
\hline HF Word & & LF Word & & Legal Nonword & & Illegal Nonword & \\
\hline $\begin{array}{l}\text { BLOCK/BLOCK } \\
\text { BIRTH/BIRTH } \\
\text { CLOTH/CLOTH } \\
\text { CHAIR/CHAIR } \\
\text { DRILL/DRILL } \\
\text { FRONT/FRONT } \\
\text { GREEN/GREEN } \\
\text { WHITE/WHITE } \\
\text { PRICE/PRICE } \\
\text { TRUCK/TRUCK } \\
\text { DEATH/DEATH } \\
\text { FLOOR/FLOOR } \\
\text { THREE/THREE } \\
\text { PLACE/PLACE } \\
\text { NORTH/NORTH } \\
\end{array}$ & $\begin{array}{l}601 \\
568 \\
610 \\
580 \\
583 \\
575 \\
599 \\
609 \\
600 \\
613 \\
611 \\
600 \\
624 \\
632 \\
593 \\
\end{array}$ & $\begin{array}{l}\text { BATHE/BATHE } \\
\text { BIRCH/BIRCH } \\
\text { CLEAT/CLEAT } \\
\text { CHUTE/CHUTE } \\
\text { DIRGE/DIRGE } \\
\text { FARCE/FARCE } \\
\text { GNOME/GNOME } \\
\text { WINCH/WINCH } \\
\text { PRANK/PRANK } \\
\text { TORCH/TORCH } \\
\text { DWARF/DWARF } \\
\text { FLUTE/FLUTE } \\
\text { THIGH/THIGH } \\
\text { PLUMB/PLUMB } \\
\text { NOOSE/NOOSE } \\
\end{array}$ & $\begin{array}{l}591 \\
642 \\
633 \\
592 \\
705 \\
623 \\
598 \\
599 \\
607 \\
594 \\
622 \\
602 \\
620 \\
662 \\
627 \\
\end{array}$ & $\begin{array}{l}\text { BLOSH/BLOSH } \\
\text { BARCH/BARCH } \\
\text { CLOAR/CLOAR } \\
\text { CHEAM/CHEAM } \\
\text { DRASH/DRASH } \\
\text { FRANT/FRANT } \\
\text { GRAIM/GRAIM } \\
\text { WHOCE/WHOCE } \\
\text { PRING/PRING } \\
\text { TRIND/TRIND } \\
\text { DRICH/DRICH } \\
\text { FRONE/FRONE } \\
\text { THIRP/THIRP } \\
\text { PLARD/PLARD } \\
\text { NIRTH/NIRTH } \\
\end{array}$ & $\begin{array}{l}610 \\
568 \\
599 \\
630 \\
626 \\
652 \\
655 \\
596 \\
671 \\
630 \\
588 \\
610 \\
623 \\
655 \\
614 \\
\end{array}$ & $\begin{array}{l}\text { BHOSL/BHOSL } \\
\text { BCRAH/BCRAH } \\
\text { CRLAO/CRLAO } \\
\text { CMHAE/CMHAE } \\
\text { DHSAR/DHSAR } \\
\text { FTNRA/FTNRA } \\
\text { GMREA/GMREA } \\
\text { WCHOE/WCHOE } \\
\text { PGNIR/PGNIR } \\
\text { TDRIN/TDRIN } \\
\text { DHCRI/DHCRI } \\
\text { FNREO/FNREO } \\
\text { TPRIH/TPRIH } \\
\text { PDRAL/PDRAL } \\
\text { NTHRI/NTHRI } \\
\end{array}$ & $\begin{array}{l}669 \\
676 \\
643 \\
641 \\
680 \\
689 \\
676 \\
632 \\
660 \\
635 \\
710 \\
720 \\
696 \\
713 \\
677 \\
\end{array}$ \\
\hline \multicolumn{8}{|c|}{ "Different" Items } \\
\hline HF Word & & LF Word & & Legal Nonword & & Illegal Nonword & \\
\hline $\begin{array}{l}\text { BLAME/FLAME } \\
\text { BEACH/TEACH } \\
\text { DRAFT/CRAFT } \\
\text { CRIME/PRIME } \\
\text { COAST/TOAST } \\
\text { FAINT/PAINT } \\
\text { GRADE/TRADE } \\
\text { WASTE/HASTE } \\
\text { POUND/FOUND } \\
\text { TREAT/GREAT } \\
\text { DREAM/CREAM } \\
\text { FLOOD/BLOOD } \\
\text { TRAIN/BRAIN } \\
\text { PAUSE/CAUSE } \\
\text { NIGHT/LIGHT }\end{array}$ & $\begin{array}{l}680 \\
672 \\
617 \\
687 \\
667 \\
682 \\
692 \\
711 \\
771 \\
688 \\
680 \\
698 \\
672 \\
656 \\
629\end{array}$ & $\begin{array}{l}\text { BEAST/FEAST } \\
\text { BRASH/TRASH } \\
\text { DOUGH/COUGH } \\
\text { COUCH/POUCH } \\
\text { CRAMP/TRAMP } \\
\text { FLANK/PLANK } \\
\text { GRILL/TRILL } \\
\text { WEDGE/HEDGE } \\
\text { PINCH/FINCH } \\
\text { TRIPE/GRIPE } \\
\text { DRAWL/CRAWL } \\
\text { FLARE/BLARE } \\
\text { TRIBE/BRIBE } \\
\text { PURSE/CURSE } \\
\text { NYMPH/LYMPH }\end{array}$ & $\begin{array}{l}655 \\
675 \\
636 \\
675 \\
664 \\
655 \\
657 \\
683 \\
690 \\
655 \\
663 \\
665 \\
679 \\
673 \\
686 \\
\end{array}$ & $\begin{array}{l}\text { BLACE/FLACE } \\
\text { BRICH/TRICH } \\
\text { DOUSK/COUSK } \\
\text { COULK/POULK } \\
\text { CHOUP/THOUP } \\
\text { FLAST/PLAST } \\
\text { GRAIM/TRAIM } \\
\text { WODGE/HODGE } \\
\text { PANCH/FANCH } \\
\text { TREAL/GREAL } \\
\text { DREAT/CREAT } \\
\text { FREAN/BREAN } \\
\text { TRABE/BRABE } \\
\text { PAUBE/CAUBE } \\
\text { NARTH/LARTH }\end{array}$ & $\begin{array}{l}666 \\
687 \\
681 \\
684 \\
689 \\
733 \\
685 \\
654 \\
679 \\
619 \\
666 \\
648 \\
650 \\
652 \\
653 \\
\end{array}$ & $\begin{array}{l}\text { BCLAE/FCLAE } \\
\text { BCRIH/TCRIH } \\
\text { DSKOU/CSKOU } \\
\text { CKLOU/DKLOU } \\
\text { CPUOH/TPUOH } \\
\text { FSTAL/PSTAL } \\
\text { GMRAI/TMRAI } \\
\text { WHDEO/HGDEO } \\
\text { PCHNA/FCHNA } \\
\text { TLRAE/GLRAE } \\
\text { DTRAE/CTRAE } \\
\text { FNREA/BNREA } \\
\text { TRBAE/BRBAE } \\
\text { PBUAE/CBUAE } \\
\text { NTRHA/LTRHA } \\
\end{array}$ & $\begin{array}{l}683 \\
673 \\
664 \\
631 \\
709 \\
683 \\
654 \\
711 \\
704 \\
636 \\
628 \\
641 \\
627 \\
658 \\
627 \\
\end{array}$ \\
\hline
\end{tabular}

Note $-H F=$ high frequency, $L F=$ low frequency. 